\title{
Anesthetic Management of Humerus Fracture with Multiple Trauma and Pneumothorax
}

\author{
*Nirmal Kumar Gyawali ${ }^{1}$, Prastuti Sharma ${ }^{2}$ \\ ${ }^{1}$ Consultant Anethesiologist Western Hospital Nepalgunj \\ ${ }^{2}$ Nepalgunj Medical College, Kathmandu University, Nepal
}

\begin{abstract}
Background: Trauma is a significant health problem and a leading cause of death in all age group.

Methodology: In this study, we describe anaesthetic management of polytrauma with pneumothorax in a 55 years old male with humerus fracture.

Result: Patient with multiple trauma with pneumothorax was safely anaesthetized with regional anaesthesia. This procedure also prevented progression of pneumothorax to tension pneumothorax.

Conclusion: Regional anaesthesia is a safe alternative of general anaesthesia in case of a patient with pneumothorax for the upper limb surgery.
\end{abstract}

Keywords: Supraclavicular Brachial plexus block, Axillary Brachial plexus block, Pneumothorax

\section{*Corresponding Author:}

\section{Dr. Nirmal Kumar Gyawali}

Email: nkgyawali@gmail.com, Phone: 081415277, Mobile: 9858021961

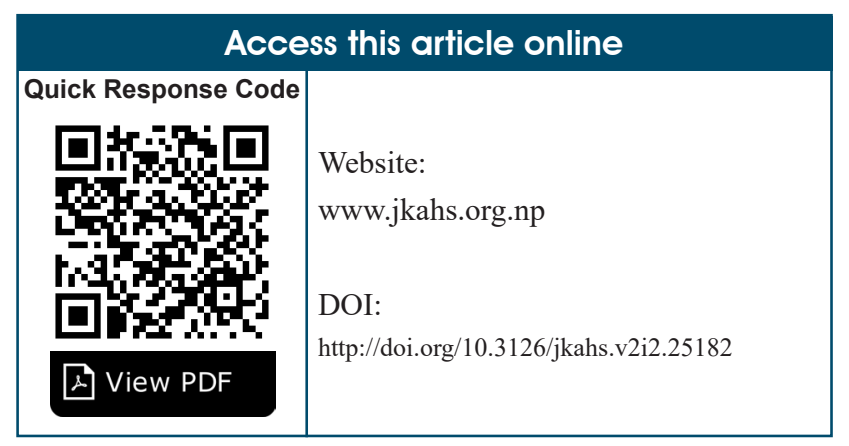

INTRODUCTION

Multiple traumas with rib fractures and pneumothorax is common after major accidents. This is a case of multiple traumas which occurred due to stone grinding machine accident. The patient developed traumatic pneumothorax following multiple ribs fracture. Traumatic pneumothorax is the condition in which there is air in the pleural space resulting from trauma and causes partial or complete lung collapse. As in this situation, pneumothorax was simple and unilateral, the patient was tolerating other injury he had like fracture of right humerus, right distal radius, right scapula and right clavicle. After resuscitation and conservative management, surgery of humerus platting along with

\begin{tabular}{|l|}
\multicolumn{1}{c|}{ Article Info. } \\
\hline How to cite this article? \\
\hline $\begin{array}{l}\text { Gyawali NK, Sharma P. Anesthetic Management of Humerus Fracture } \\
\text { with Multiple Trauma and Pneumothorax. Journal of Karnali Academy } \\
\text { of Health Sciences. 2019;2(2):144-146 }\end{array}$ \\
\hline Received: 4 May, Accepted: 14 July, Published: 30 August 2019 \\
\hline Conflict of Interest: None, Source of Support: None \\
\hline
\end{tabular}

bone grafting and distal radius close reduction and $\mathrm{k}$ wiring was done under regional anesthesia. Patient with multiple trauma requiring surgery pose a number of challenges for anaesthesiologist. Here we present the successful perioperative management of a patient with multiple injuries including pneumothorax, who had undergone humerus plating with bone grafting. The presence of pneumothorax and multiple rib fracture impacted our dicision making because of the increased risk of expanding the pneumothorax with positive pressure ventilation. The development of tension pneumothorax intraoperativly requiring emergency chest tube insertion has been reported. ${ }^{1}$ 


\section{CASE REPORT}

A 55 year old male named Kallu Saud from Lalpur goda, Kailali working in a stone crusher factory got sustained injury while working with machine on 16th May 2019 around 1 AM. He was taken to the Padma Hospital Kailali at 2 AM, after primary resuscitation he was referred to Western Hospital Nepalgunj. He arrived at Western Hospital Nepalgunj on same day at $1 \mathrm{PM}$.

At the time of presentation, the patient's vital was systolic blood pressure $80 \mathrm{~mm}$ of hg, diastolic blood pressure $50 \mathrm{~mm}$ of hg and pulse 100 per minute with dyspnoea and severe pain. Oxygen saturation was $92 \%$ without oxygen. After doing primary survey, IV line was established with 18 gauze cannula and 2 litres ringer's lactate was given and catheterization was done with proper sized Foley's catheter and oxygen was given by nasal cannula. Once the patient's general condition was improved he was sent for x-ray, CT scanning and blood test. X- ray and CT scan revealed multiple injuries like fractures humerus right side (fig 1), distal radius right side (fig.2), clavicle right side, scapula right side (fig 3) and multiple ribs fracture right side (fig 4) with right sided pneumothorax (fig 5). According to the decision of Doctor's team, patient was kept under conservative management. After 20 days of conservative management, patient's lung fully expanded and then he was planned for humerus plating and bone grafting along with close reduction and $\mathrm{k}$ wire fixation for radius fracture. Patient was kept nil orally for 8 hours and brought to OT at $2 \mathrm{pm}$ on 29th may. In operating room after attaching monitors, supraclavicular brachial plexus block was given with $5 \mathrm{ml}$ of $0.5 \%$ plain bupivacaine mixed with $5 \mathrm{ml}$ xylocaine with adrenaline and $10 \mathrm{ml}$ normal saline, supraclavicular brachial plexus block supplemented by axillary route of brachial plexus block with same dose of local anesthetic and normal saline. For bone grafting spinal anesthesia was given with $0.5 \%$ heavy bupivacaine $3 \mathrm{ml}$, oxygen was given by nasal cannula. Operation was performed in supine position. Patient had mild discomfort, otherwise intraoperative procedure was uneventful and this discomfort was relieved by IV paracetamol 1 gram and butorphanol
$1 \mathrm{mg}$. Operation was complete in two and half hours and patient was transferred to postoperative ward, oral feeding started after 6 hours. There was no any complication after surgery and patient started to walk and perform his normal activity after three days of surgery.

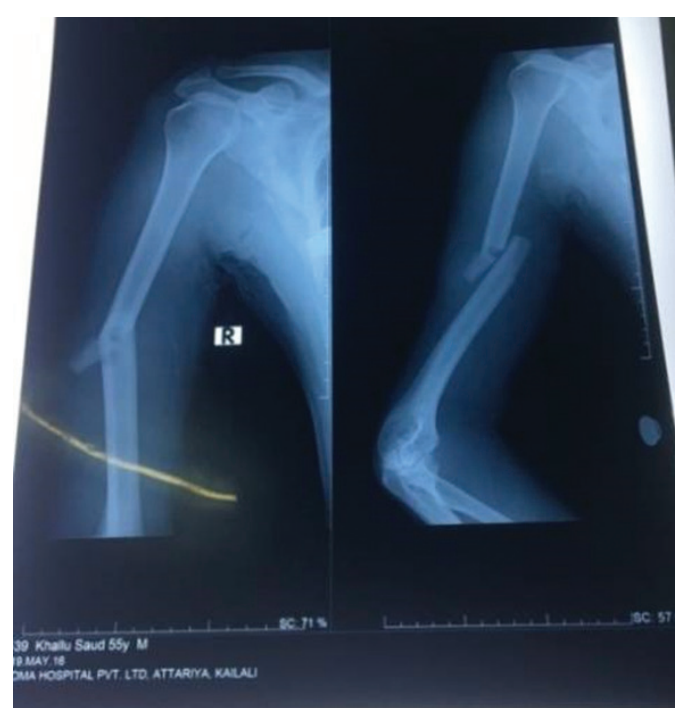

Figure 1: X-ray showing humerus fracture

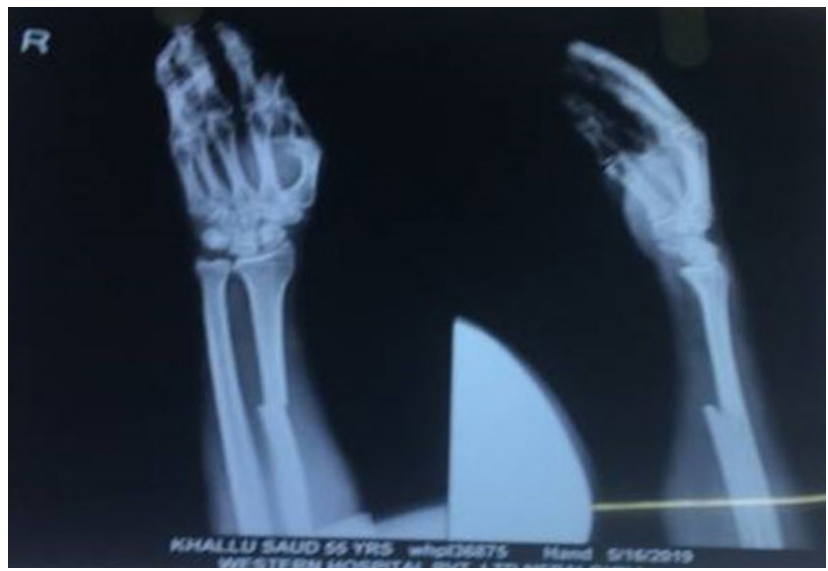

Figure 2: X-ray showing distal radius fracture

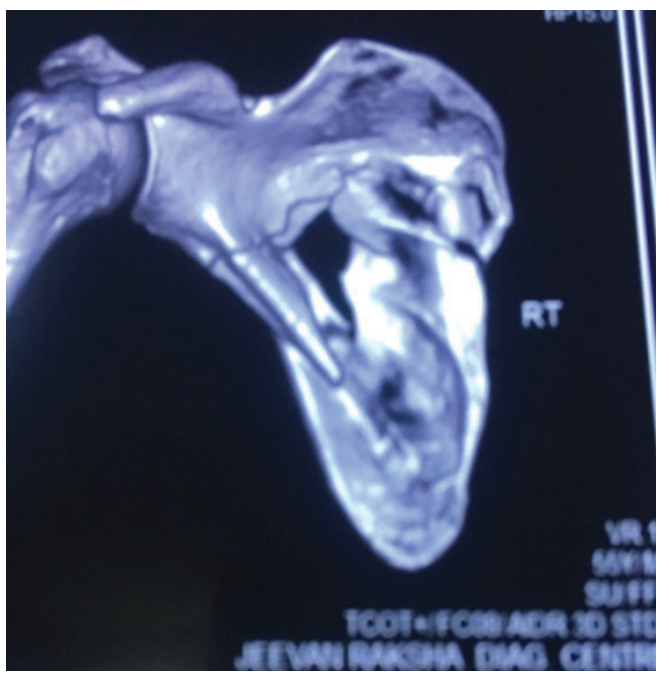

Figure 3: Xray showing right scapula fracture 


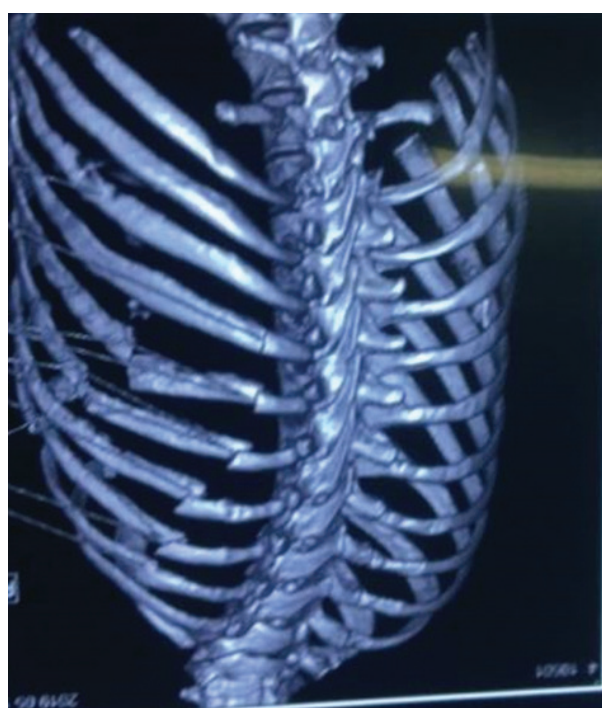

Figure 4: X-ray showing multiple rib fracture

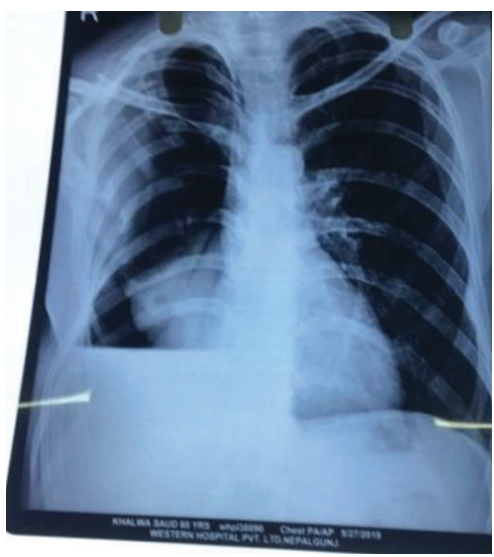

Figure 5: X-ray showing pneumothorax

\section{DISCUSSION}

Regional anesthesia confers a variety of benefit to trauma patient. In addition to improving patient comfort, nerve and neuroaxial blockade significantly reduces the requirement for systemic opioid analgesia and adverse effects associated with opioid use. As this patient presented with pneumothorax at time of hospital admission after few days of conservative management there was not visible pneumothorax on chest $\mathrm{x}$-ray but still threat of occult pneumothorax existed.

The intraoperative progression of a simple or occult pneumothorax can be a devastating clinical scenario. During general anesthesia and positive pressure ventilation a simple pneumothorax can transit into a tension pneumothorax. At the time of trauma, the patient had suffered ribs fractures and was diagnosed with pneumothorax. Presumably, a previous unrecognized visceral pleural laceration related to the original trauma caused an air leak, resulting in the tension pneumothorax. ${ }^{2}$ Plourde et al studied a cohort of 450 patients with thoracic trauma. ${ }^{3}$ Pneumothorax is an uncommon and potentially dangerous problem, especially during general anesthesia, when the patient cannot complain of respiratory difficulty or pain, and with positive pressure ventilation, which increases the risk of a tension pneumothorax. ${ }^{4}$

\section{CONCLUSION}

Regional anesthesia is safer alternative for the patient with multiple traumas with pneumothorax. In addition to improving patient comfort, it reduces the requirement for systemic opioid analgesia.

\section{REFERENCES}

1. Rankin D, Mathew PS, Kurnutala LN, Soghomonyan S, Bergese SD. Tension pneumothorax during surgery for Thoracic spine stabilization in prone position: A case report and review of literature. J Investig Med High impact case rep 2014;2(2):2324709614537233 2

2. Slade M. Management of pneumothorax and prolonged air leak. Semipen Repir Crit Care Med 2014;35:706-14

3. Plourde M, Emond M, Lsvoie A, Guimont C, Le Sage N, Chauny JM et al. Cohort study on the pravalance and risk factors for delayed pulmonary complications in adults following minor blunt thoracic trauma. CJEM 2014;16:136-43

4. Fossard JP, Samet A, Meistelman C, Longrois D. Life-threatening pneumothorax of the ventilated lung during thoracoscopic pleurectomy. Can J Anesth 2001;48:493-6 